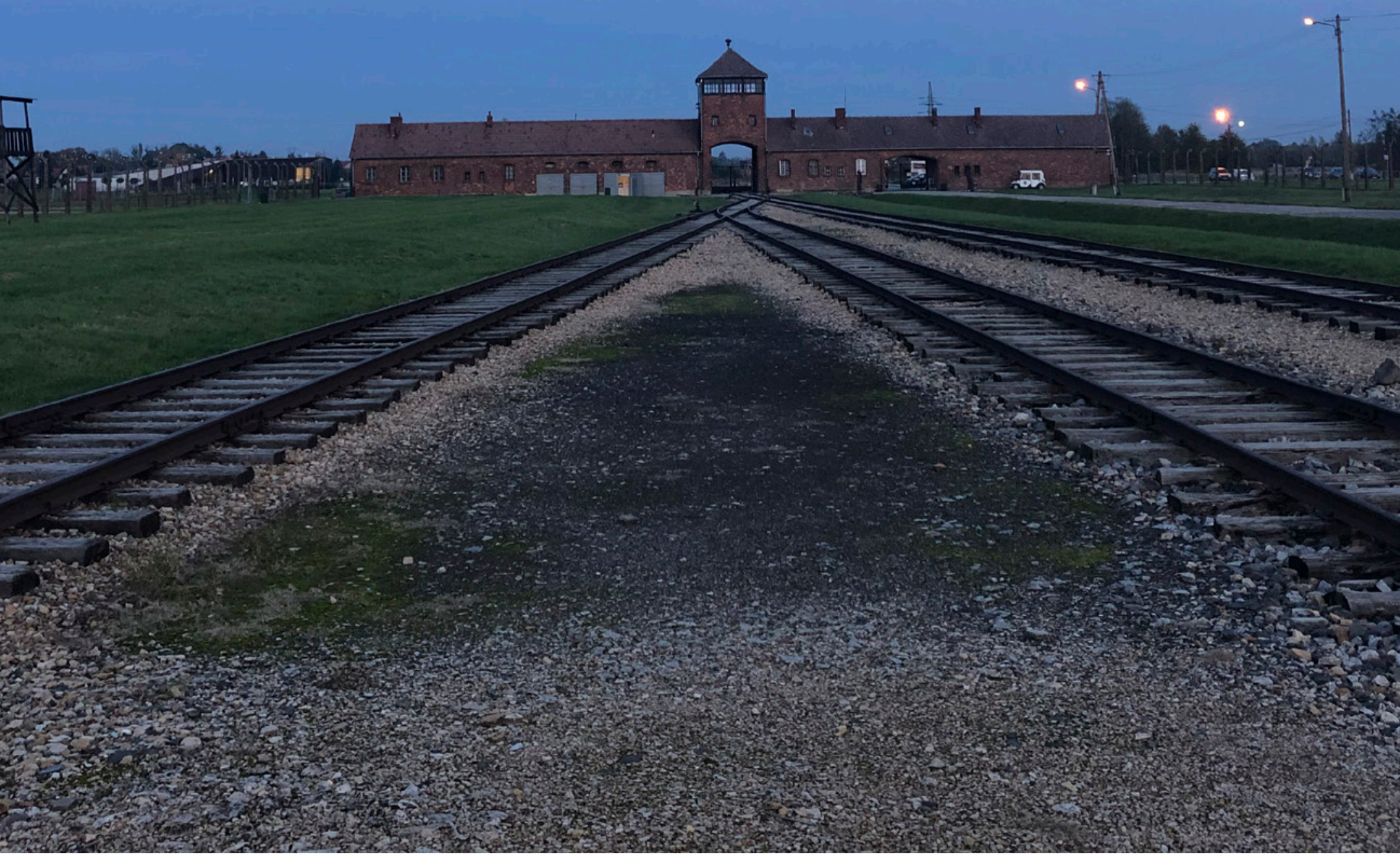

Panorámica del Museo Estatal de Auschwitz-Birkenau (Polonia). Fotografía: Ana Galán-Pérez. 


\title{
MUSEOS MEMORIALES, MUSEOS \\ DIFERENTES: BUSCANDO CLAVES PARA \\ SU CONSERVACIÓN
}

\author{
MEMORIAL MUSEUMS, SPECIAL MUSEUMS: \\ IDENTIFYING KEY FACTORS FOR \\ THEIR CONSERVATION
}

Ana Galán-Pérez

Investigadora Integrada postdoctoral en Centro de Investigação em Ciência e

Tecnologia das Artes, da EA/UCP (Oporto, Portugal)

Gestora de Colecciones en Musealia

Eduarda Vieira

Dra. Profesora Escola das Artes

Directora Centro de Investigação em Ciência e Tecnologia das Artes (CITAR)

Universidade Católica Portuguesa

Resumen

Palabras clave

Abstract

Keywords

El presente ensayo parte de la reflexión sobre los museos memoriales como museos diferentes que custodian un tipo de objetos sensibles por su origen y heterogéneos en cuanto a sus valores (tangibles e intangibles), materialidad y significancia, que requieren una nueva perspectiva por parte de los profesionales de la conservación del patrimonio.

A lo largo del artículo abordaremos varias cuestiones para identificar y comprender mejor los fines y las fórmulas que adoptan estos museos: cómo es la institución, cuál es el peso del lugar patrimonial donde se ubican y cómo se construye la significancia de las colecciones. Para ello nuestro punto de partida será el marco de construcción de la nueva definición de museos del ICOM, International Council of Museums, y la carta de Museos memoriales de Iсмемо, el Comité Internacional para Museos en Memoria de las Víctimas de Crímenes Públicos.

Museos memoriales, ética, colecciones de la memoria, significancia, conservación.

This essay is a reflection on Memorial Museums as special Museums that keep artifacts that are considered sensitive due to their origin, and diverse as regards their values (tangible and intangible), materiality and significance, which require a new perspective on the part of conservation professionals.

In this text, we will address several questions in order to identify and better understand the mission and the formulas adopted by these museums: how the institution is, how important the place where they belong is, and how the process of construction of the collection's significance is. In order to do so, our starting point is the new museum definition created by ICOM and the Charter of ICMEMO, International Committee of Memorial Museums in Remembrance of the Victims of Public Crimes.

Memorial Museums, Ethics, Collections of Memory, Significance, Conservation. 


\section{Introducción}

La preservación de las colecciones de la memoria es relativamente reciente, vinculada al propio devenir de una tipología especial de museos. Para poder dar respuestas a los interrogantes que suponen la construcción de criterios de conservación, es preciso conocer los museos y las comunidades que representan, su memoria, esto es, su patrimonio material e inmaterial. Conocer cómo se han formado, cuál es su misión y cuál es su relación con las comunidades de las que proceden los objetos, nos ayudará a comprender los procesos internos de los museos y también a construir una base para el razonamiento futuro en nuestras acciones.

Para tipificar este tipo de museos memoriales y acercarnos mejor a sus colecciones, podemos partir de la definición de museo que nos proporciona el ICOM, y especialmente acudir a la red Iсмемо, su Comité Internacional para Museos en Memoria de las Víctimas de Crímenes Públicos. Este último organismo nos habla de la misión y responsabilidad social y política de los museos, de sus fórmulas como institución, así como del enfoque de la museología crítica para elaborar sus narrativas históricas de respeto a las diversas memorias y su ubicación en los lugares históricos traumáticos.

\section{Definición de Museos memoriales}

Citados en las fuentes como museos trágicos, museos de patrimonio incómodo, e incluso museos de la vergüenza ${ }^{1}$, los museos memoriales se erigen para recordar el efecto de los traumas

1 Sobre más definiciones de este patrimonio: disonante, hiriente, negativo o indeseado (Ortiz García, 2011: 3), Los museos de la vergüenza: «La vergüenza entendida como la aceptación pública de la pérdida y el despojo de la dignidad humana, resultado de los excesos del poder gubernamental. Pero la vergüenza también entendida como la aceptación de las prácticas de intolerancia que los miembros de una comunidad tienen sobre los miembros de otra comunidad» (Witker Barra, 2016: 93). sufridos por las comunidades. Sus cimientos se apoyan en los vínculos del pasado para sanar el presente y conservan un patrimonio comunitario.

Sin embargo, si todos los museos son, en origen, instituciones que conservan $y$ transmiten un legado tangible e intangible de las comunidades a las que representan, ¿a qué nos referimos concretamente y qué define esta tipología de museo? Veamos la definición del ICOM de 2017, según la cual todos los museos son una institución:

sin fines lucrativos, permanente, al servicio de la sociedad y de su desarrollo, abierta al público, que adquiere, conserva, investiga, comunica y expone el patrimonio material e inmaterial de la humanidad y su medio ambiente con fines de educación, estudio y recreo.

La realidad museológica vinculada a la cultura de la remembranza, se espera quede reflejada en la nueva definición de museo del siglo XxI, actualmente en proceso de elaboración, pues sabemos que el trabajo actual del ICOM para la renovación de esta definición aporta aspectos clave de los museos memoriales, y de alguna manera posiciona y refrenda la necesidad de esta tipología:

La definición de museo debe ser clara respecto a sus objetivos y a la escala de valores que utilizan como referencia a la hora de hacer frente a retos y responsabilidades relacionados con la sostenibilidad, la ética, la política, la sociedad y la cultura del siglo $\mathrm{XXI}^{2}$.

Es decir, la ética y la sostenibilidad ocupan un lugar relevante, subrayando la responsabilidad adquirida de los museos con las comunidades, y son aspectos a reconocer por los profesionales del área de la conservación en los museos, a través de la puesta en marcha de su código deontológico profesional.

2 ICOM. Definición de Museo. Disponible en https:// icom.museum/es/recursos/normas-y-directrices/definicion-del-museo/ [Fecha de consulta 10/05/2020] 


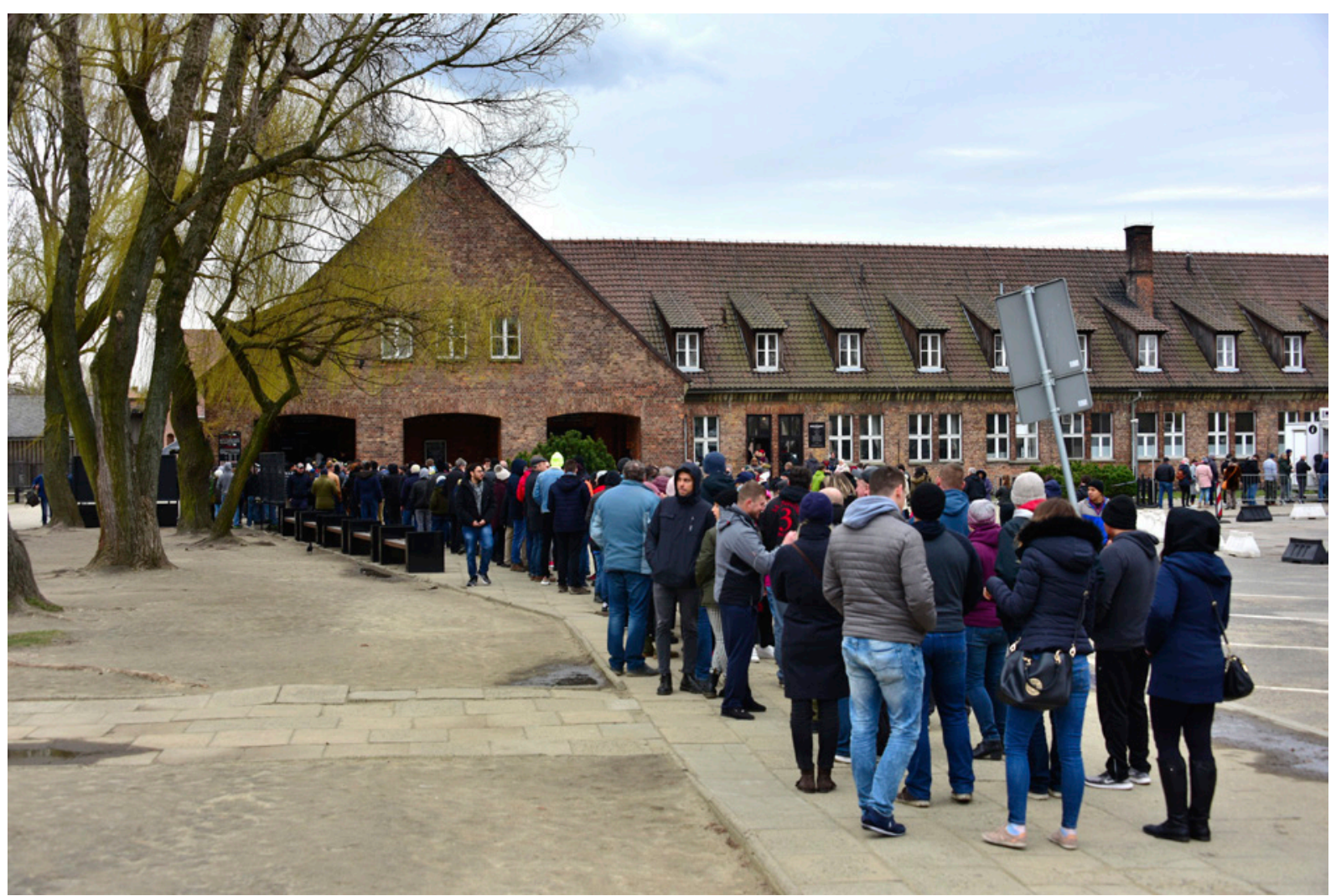

Entrada del Auschwitz-Birkenau Museum (Auschwitz I). Fotografía: «Entrance to Auschwitz-Birkenau Museum 2019» por Adrian Grycuk bajo licencia CC BY-SA 3.0 PL.

a) Respecto a la sostenibilidad, se trata de un elemento considerado por la comunidad científica tal y como sabemos del congreso de MINOM de ICOM-MINOM celebrado los días 22 y 23 de julio de 2020 en formato virtual, cuyo título recoge este fin: "Hacia una museología 4D: social, ambiental, política y económicamente sostenible ${ }^{3} »$.

b) Respecto al papel de la ética y código deontológico en la nueva definición de museo, podemos considerarlo una referencia para integrar el rol de las comunidades y su papel en la conservación. En definitiva, la base que subyace es el pensamiento holístico de las colecciones que el museo memorial preserva

3 MINOM-ICOM «Hacia una museología 4D: social, ambiental, política y económicamente sostenible». Disponible en http://www.minom-icom.net/noticias/xx-conferencia-internacional-galaico-portuguesa-minom-icom-2020 [Fecha de consulta 1/05/2020]. Asistencia 22-23 julio 2020. teniendo en cuenta a todos los agentes implicados en su colección.

Partiendo de la ética y sostenibilidad se construye un contexto más amplio en torno al patrimonio histórico, no solo por su materialidad sino por su significancia: valores sociales, antropológicos, en el que el peso de la memoria es su rasgo más importante. En definitiva, preservar la memoria para defender los derechos humanos. Es este valor el que le dota principalmente de su significancia; la memoria individual refuerza la memoria colectiva.

Sobre la producción de significados de las instituciones museísticas partiendo de la ética, el museo como ente "supraindividual», dice Navarro citando a Heinz, que tiene una responsabilidad moral hacia todos los miembros de su sociedad, pues en esta cultura de 


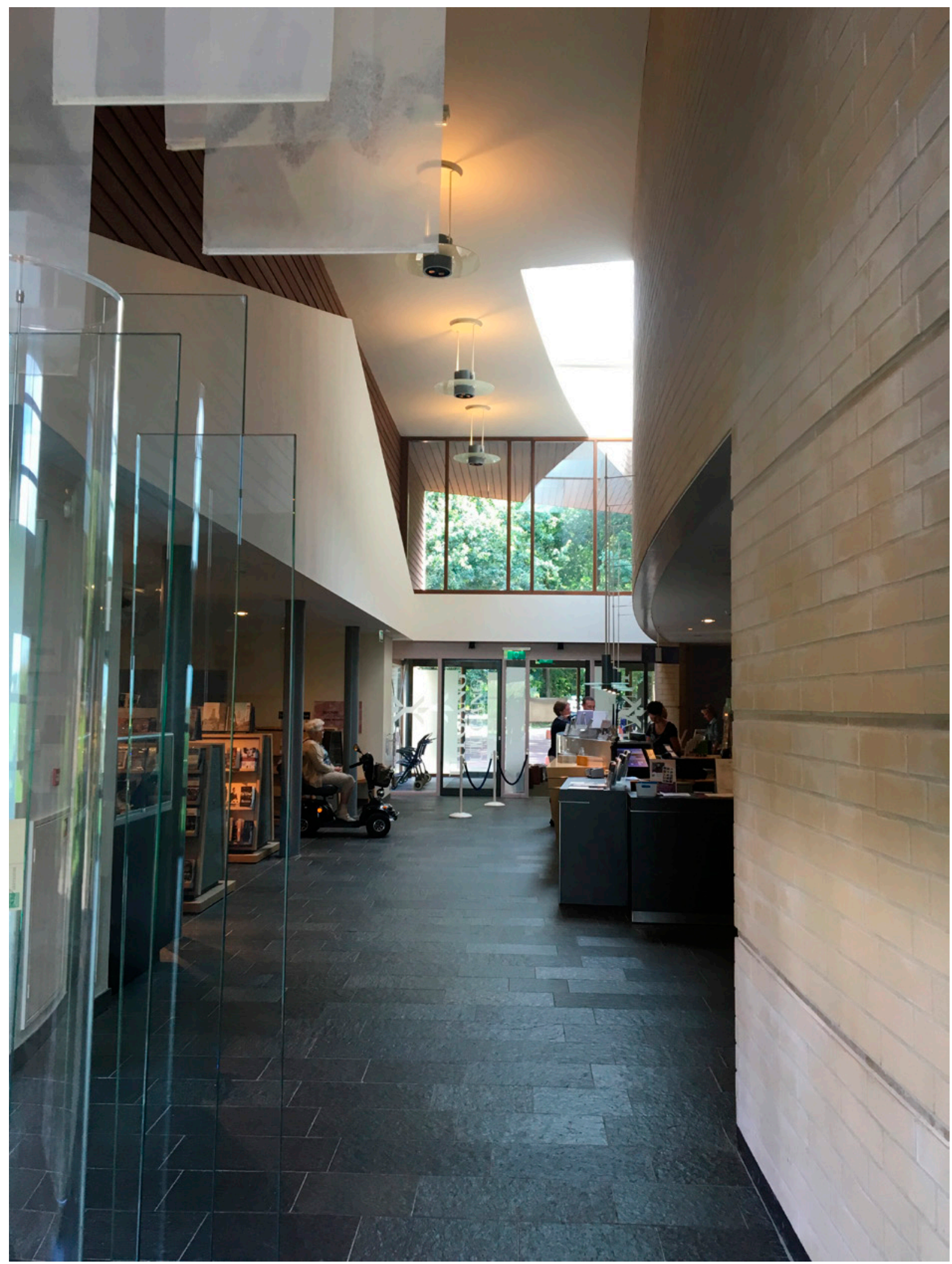

Entrada del Museo del campo de concentración de Westerbork (Holanda). Fotografía: «Entree museum herinneringscentrum» por Hanno Lans bajo licencia CC BY 4.0. 
la remembranza los museos «tratan con la memoria, la historia, la representación de la identidad y la construcción de la alteridad» (Navarro, 2011: 53).

En el marco del ICOM y en el año 2001 se creó el ICMEMO ${ }^{4}$, el Comité Internacional para $\mathrm{Mu}$ seos en Memoria de las Víctimas de Crímenes Públicos, estableciendo como objetivo, coincidente con la unESCO «... mantener el deber de memoria y promover la colaboración cultural dándole más importancia a la enseñanza y poniendo los conocimientos al servicio de la paz».

Asimismo, plantea en su propia definición su misión, pues «se dedican a la conmemoración de las víctimas de crímenes de Estado, de crímenes cometidos con el consentimiento de la sociedad o en nombre de motivos ideológicos».

Sobre el espacio museístico, el comité especifica que «se sitúan en el sitio donde fueron cometidos esos crímenes o en lugares elegidos por los supervivientes con el objetivo de la conmemoración».

En relación a las comunidades y la preservación de la memoria, nos dice que: «pretenden dar a conocer los acontecimientos del pasado situándolos en un contexto histórico creando a la vez fuertes vínculos con el presente».

En los estatutos fundacionales de la red Iсмемо, nos dicen que los Museos de Sitio Histórico y Museos Memoriales de los crímenes públicos contra la humanidad:

... son instituciones que trabajan como museos con una colección de objetos históricos, que generalmente integran edificios, y que trabajan en las áreas tradicionales de los museos: acumular, preservar, exhibir, investigar y educar. Están concebidos como memoriales exhortando a los visitantes para que protejan los derechos humanos básicos, y cooperan con las víctimas y otros testigos contemporáneos, tomando por tanto

4 Iсом. Iсмемо, el Comité Internacional del ICOM para Museos en Memoria de las Víctimas de Crímenes Públicos. Disponible en https://icom.museum/es/committee/comite-internacional-para-museos-en-memoria-de-las-victimas-de-crimenes-publicos/ [Fecha de consulta 10/05/2020] un cariz psico-social especial. Sus esfuerzos por transmitir información sobre hechos históricos están moralmente cimentados y aspiran a definir una relación con el presente, sin abandonar una perspectiva histórica» (2001: 3).

Por tanto, son un tipo de museos conmemorativos, que rememoran un hecho histórico. Esto hace que hablemos de una tipología especial de museo en el marco de la historia contemporánea, pero cuya misión está alejada de mostrar los avances tecnológicos de una civilización; más bien al contrario, refleja los efectos de la destrucción sobre la misma provocados desde las propias sociedades. Así, tienen una importante misión crítica y ética para que no se vuelvan a producir situaciones del pasado.

Si un rasgo caracteriza los museos de la memoria, o a una buena parte de ellos, es su emplazamiento en los lugares históricos donde ocurrieron los hechos trágicos. Los espacios son en sí mismos un elemento patrimonial en los que los museos se apoyan para conducir su tarea educativa y cívica. Son una herramienta en primer orden, que junto al museo forman paisajes patrimoniales de la memoria y atendiendo a la Carta de los Museos Memoriales ${ }^{5}$, este gran potencial didáctico integrado en el discurso narrativo del museo debe ir dirigido hacia la representación de valores y principios universales. Esto supone integrar los conceptos de paz y la defensa de los derechos humanos en la construcción de un contenido, además de consensuarlo con todas las partes implicadas, utilizando el hecho de su localización en el lugar histórico.

5 Artículo 9. «Los museos memoriales que se ubican en lugares históricos auténticos donde se cometieron los crímenes, ofrecen una gran oportunidad para conducir la educación cívica e histórica, aunque hay también grandes riesgos. Es por ello que los museos memoriales necesitan orientar su trabajo educativo menos hacia el acuerdo del contenido y más hacia principios universales. Esto requiere que los visitantes no se vean sobrecogidos o adoctrinados por el contenido, que se respeta el punto de vista subjetivo de los individuos, y que esos temas controvertidos son tratados efectivamente como controvertidos». 


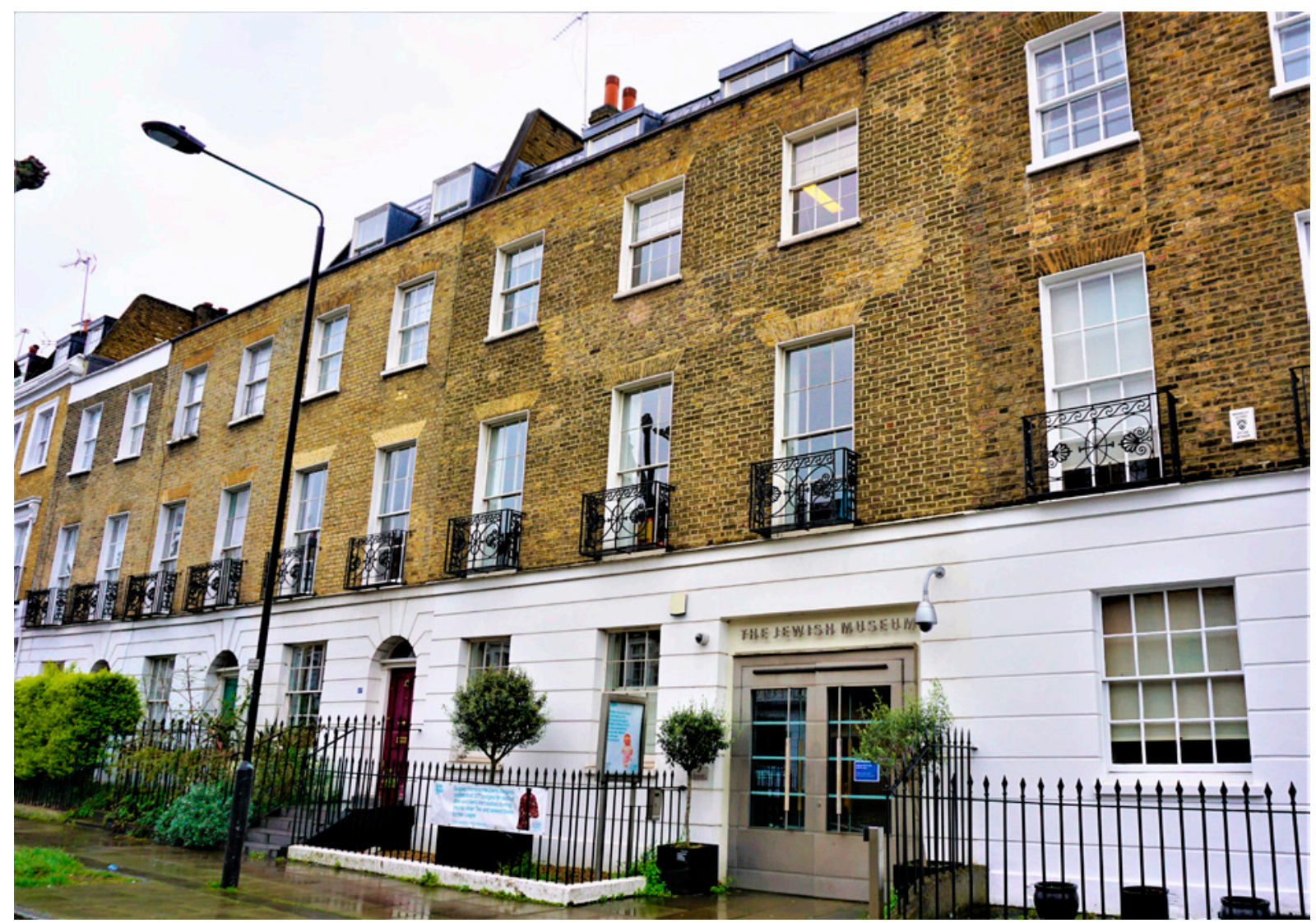

Panorámica exterior del Jewish Museum of London (Inglaterra). Fotografía: «Jewish Museum London - Joy of Museums» por Joyofmuseums bajo licencia CC BY-SA 4.0.

Entonces, podemos decir que los museos memoriales se identifican por el interés en representar la realidad de minorías que han sufrido crímenes públicos, que muestran un vínculo especial con el espacio y los lugares donde ha ocurrido el hecho traumático, y una fuerte carga ética y de responsabilidad social respecto a las comunidades agraviadas pero también con las sociedades presentes en la defensa de los derechos humanos.

\section{Diversidad museológica para preservar la barbarie}

Las formas múltiples que pueden seguir los museos para activar la memoria y promover la autocrítica proceden de la situación traumática: «genocidios, represión, discriminación, explotación, pandemias, situaciones de sufrimiento social, causadas por desastres ambientales o eventos climatológicos, situaciones cotidianas o extremas de desigualdad o de intolerancia entre otros» (Maceira, 2012: 87). Por tanto, los museos memoriales abordan el trauma surgido por la pérdida de vidas humanas y los efectos de la limitación o anulación de los derechos humanos universales, afectando sobre todo a grupos en minoría: por pensamiento político, por religión, por cultura, por etnia, o por no cumplir con los estándares sociales determinados por el régimen totalitario en el poder.

Un primer acercamiento a los museos que forman parte de la red ICMEMO $^{6}$ nos indica

6 ICMEMo-Miembros. Disponible en http://icmemo.mini.icom. museum/about/other-members [Fecha de consulta 12/05/2020] 


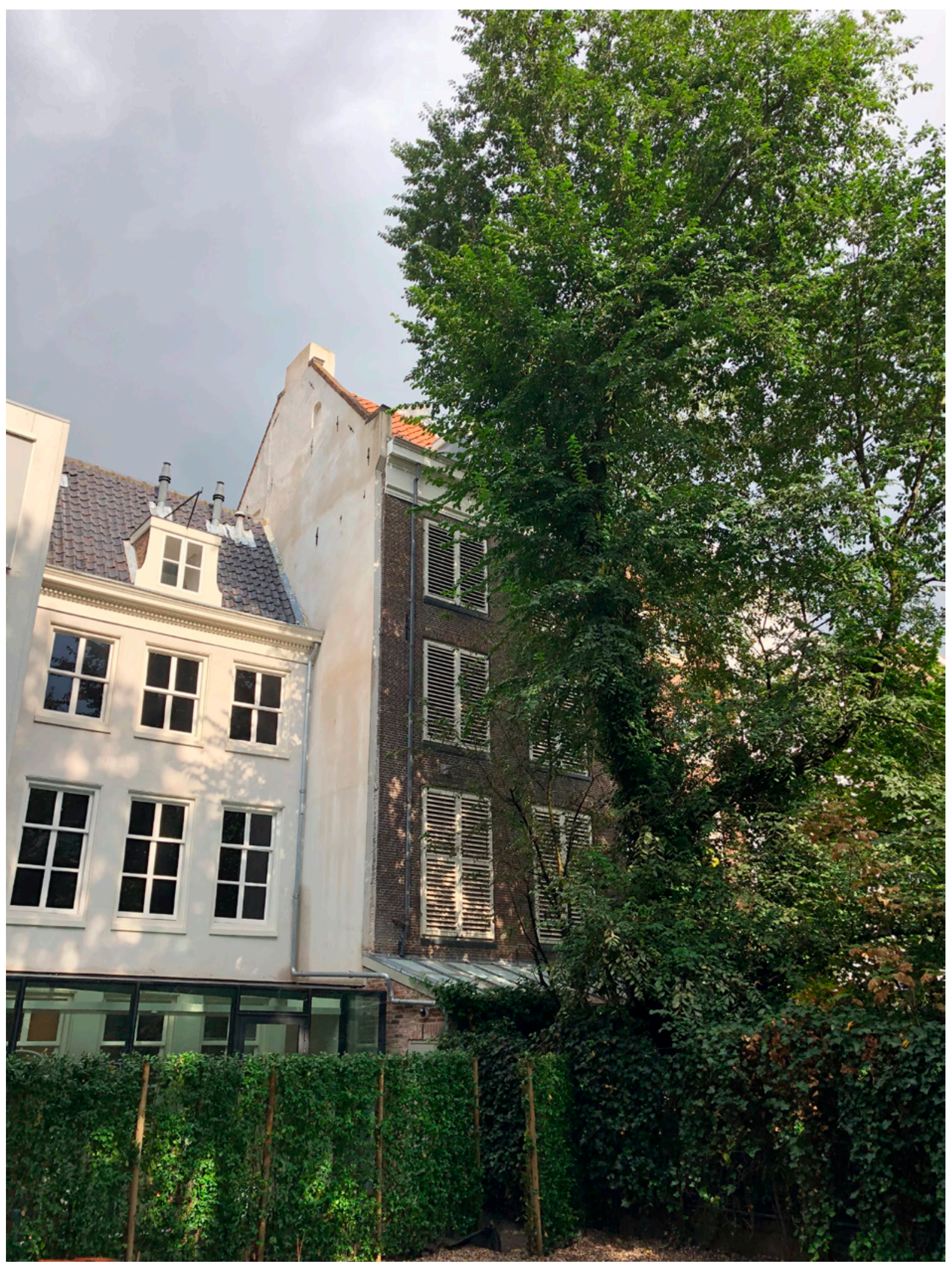

Casa Museo de Ana Frank (Ámsterdam). Vista desde el patio interior. Fotografía: Ana Galán-Pérez. 
cierta heterogeneidad en este tipo de museos de la memoria y espacios de la barbarie musealizados, como el Auschwitz-Birkenau State Museum (Polonia), Museo de la Paz de Gernika (España), Museum of Gulag (Rusia), entre otros ${ }^{7}$.

$\mathrm{Si}$ atendemos a las fuentes, autores como Hernández (2011), Velázquez (2011), Williams (2007), Winstone (2010), observan pluralidad en los diversos museos memoriales, e identifican el germen de este tipo de museos a partir de las instituciones que han musealizado lugares del Holocausto nazi. Este grupo de museos han sido la referencia para los museos de la memoria ante crímenes públicos y de los que hay numerosos ejemplos en Latinoamérica. También Luz Maceira (2012: 73), al hablar sobre museos, memoria y derechos humanos, cita los museos de historia social, museos de la paz, museos de derechos humanos, museos comunitarios, museos de sitio, y museos conmemorativos.

El autor Martin Winstone (2010: 11) realiza una revisión de los lugares del Holocausto en Europa, país por país, y clasifica de la siguiente manera: "campos de concentración y de exterminio. Campos de tránsito; lugares de masacre; ciudades y guetos; centros de eutanasia; lugares de Sinti y Roma "campos gitanos"; museos y memoriales de víctimas del holocausto».

A su vez, Hernández (2011: 81) plantea la existencia de: «museos artefactuales; poliorcética e infraestructura militares; museos monográficos y centros de interpretación vinculados a campos de batalla ${ }^{8}$; espacios conmemorativos: cementerios militares, memoriales

\footnotetext{
7 Preserving Collections of Memory. Disponible en https:// preservingmemorycollections.org/memorial-museumsworld/ [Fecha de consulta 3/07/2020]

8 Sobre la musealización de los campos de batalla, Hernández alude al ejemplo del Consorcio Memorial de los Espacios de la Batalla del Ebro (сомевE) creado por la Generalitat de Catalunya, cuyo fracaso alude a causas como la inviabilidad institucional por sobredimensionamiento, la ausencia de método científico, ausencia de investigación arqueológica, y falta de control ante los actos de furtivismo.
}

y monumentos conmemorativos». También podemos identificar los museos de la resistencia, como ejemplo de una buena proliferación de esta tipología en Yugoslavia, Grecia, Polonia, Francia e Italia (Hernández, 2011: 85).

En esta búsqueda de clasificación mediante rasgos identificatorios de los museos de la memoria, Velázquez (2011: 28-29) reflexiona y aporta ciertos matices sobre los elementos planteados por Williams (2007) e incluso algunos de ellos son coincidentes en la Carta de Museos Memoriales que hemos analizado en párrafos anteriores.

Respecto a la vinculación de los museos memoriales al lugar donde se ubican, que defiende Williams, además de la participación de un público habitual con el museo, o constituirse como un lugar donde desarrollarse actividades de especial relevancia política por parte de las comunidades, Velázquez argumenta que son rasgos compartidos con las instituciones museísticas en sí mismas, puesto que los museos se ubican allí donde enraízan con la comunidad que representan, y pone el ejemplo de los museos de arte y antropología que «reflejan posturas políticas como estrategias de legitimación como estrategia de legitimación del régimen que les dio la vida y la creación de identidades colectivas de representación» (Velázquez, 2011:28).

Sin embargo, el rasgo definitorio de estos museos es el apoyo de las víctimas, pues los museos memoriales a diferencia de los demás museos de historia ${ }^{9}$, respaldan en el presente procesos de apoyo a las minorías en la búsqueda de la justicia, así como la función pedagógica de lugar de memoria y remembranza y sanamiento social que

\footnotetext{
9 «Los museos de historia convencional, historia nacional son centros de civismo, lugares donde se afilia al visitante a los principios morales de estado, de la soberanía, los llamados valores nacionales (unidad, identidad); el problema es de qué tipo de enseñanza moral se está hablando, qué tipo de pensamiento crítico fomenta y qué juicios establece sobre la historia y el presente» (Velázquez, 2011:29).
} 


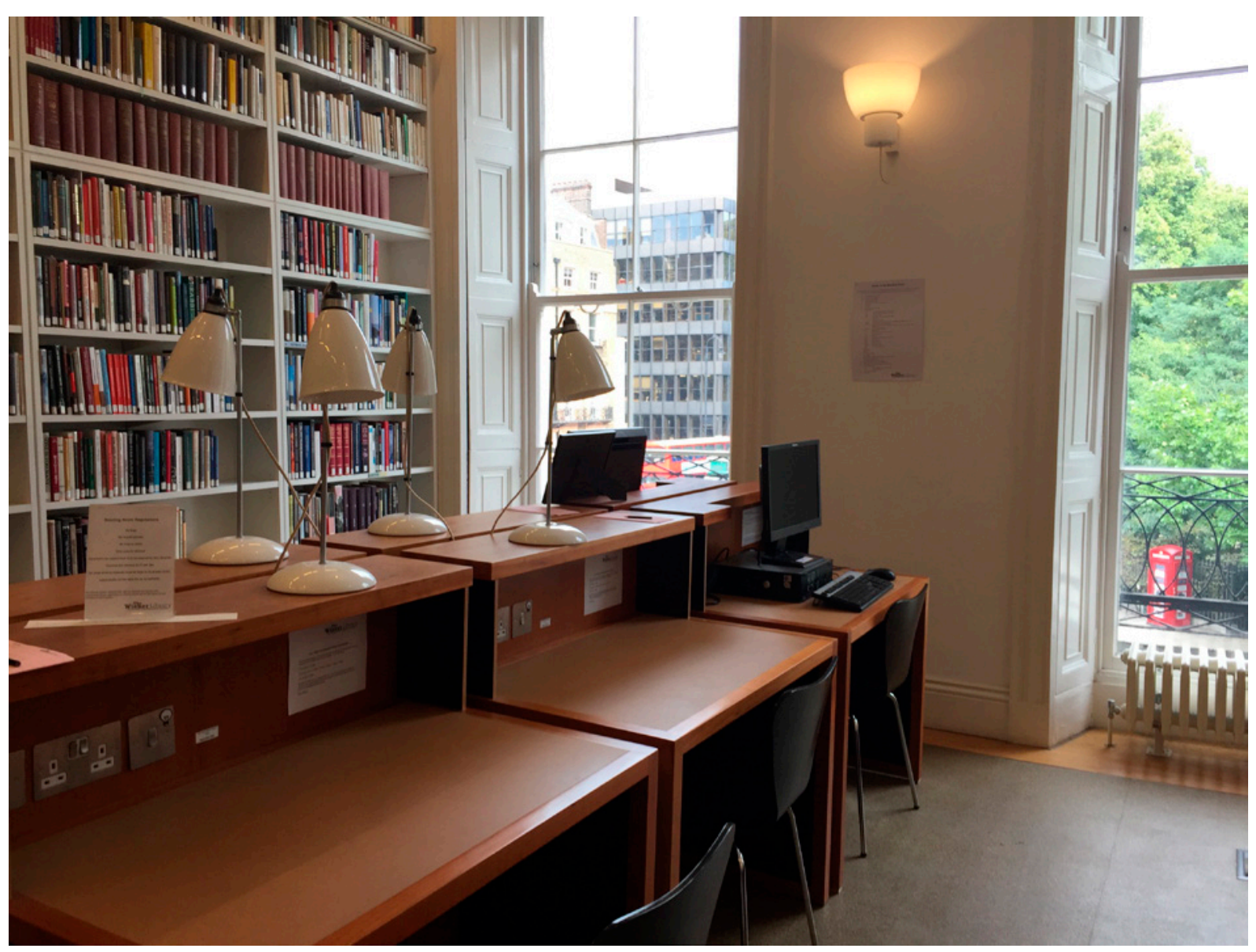

Familiares de víctimas y supervivientes acuden a sus archivos para obtener información. Museo y Archivo Wiener Library (Londres). Fotografía: Ana Galán-Pérez.

supone el contacto con las víctimas y sus familiares a través de los programas específicos de actividades. En este diálogo y patrimonialización del trauma con toda su carga intangible, los objetos individuales pasan a ser colecciones representativas de un mayor espectro de la sociedad, a través del proceso legitimador del museo. $\mathrm{Y}$ es en este proceso de apoyo a las víctimas y organizaciones civiles, y de reivindicación de aspectos pendientes de juicio y todavía no tratados por los museos tradicionales de historia, son los que ambos autores coinciden como rasgo identificatorio (Velázquez, 2011: 29).

Los lugares de la memoria han progresado hasta su patrimonialización, no solo material sino inmaterial, y es en este aspecto en el que la museología crítica tiene un peso relevante. Las reflexiones sobre la patrimonialización de la guerra ayudan a construir las estrategias museológicas. Destaca Xavier Roigé (2008: 24) que ha habido una evolución en la narrativa, y que si anteriormente se subrayaba la glorificación de hechos militares y el propio ejército (Hernández, 2004) en la actualidad el pensamiento crítico construye discursos conducentes a mostrar la «fragilidad de la paz».

Encontramos en las fuentes obras que reflexionan sobre la musealización de la barbarie y se preguntan si todo se puede patrimonializar. El caso de la guerra y sus testimonios es recurrente, y de nuevo se apoya 


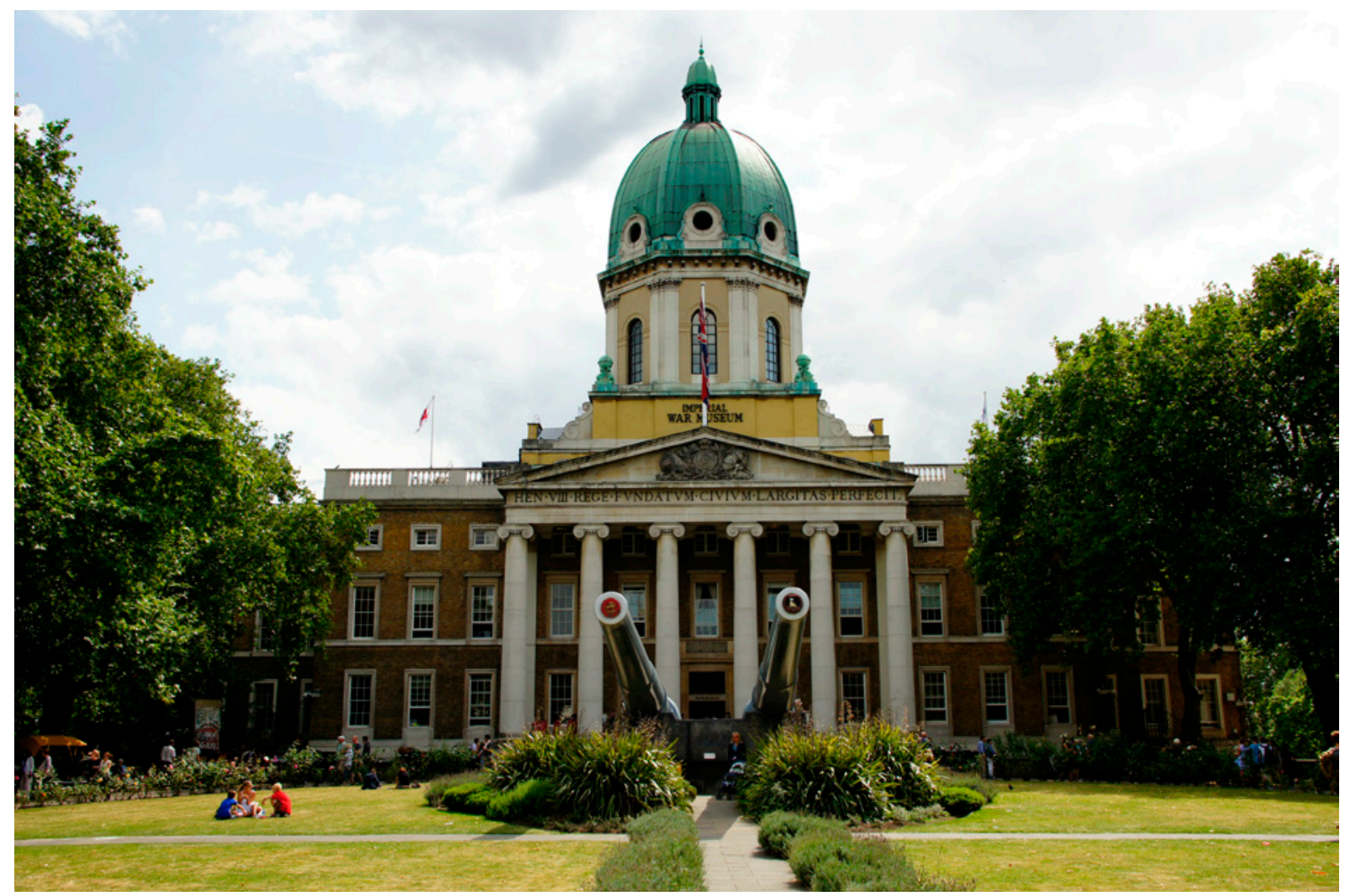

Panorámica exterior del Imperial War Museum (Londres). Fotografía: «Imperial War Museum, London (geograph 4108048)» por Peter Trimming bajo licencia CC BY-SA 2.0.

el cambio de paradigma en la narrativa: se necesita una mirada distinta que respecto a los discursos tradicionales patrióticos, cambie y ayude a «comprender la violencia organizada y su superación». De la misma manera que en el párrafo anterior, que ayude a comprender la guerra y a fomentar la paz (Maceira, 2012: 96).

Por tanto, múltiples formas museísticas para la reflexión y la construcción de narrativas contemporáneas éticas sobre la barbarie y la guerra, de la defensa de las víctimas y los derechos humanos, así como la búsqueda de la sostenibilidad y la conservación de su legado material.

\section{Las colecciones y su preservación}

En términos generales, podemos decir que los museos son instituciones que gozan de aprecio social porque se les reconoce una capacidad científica y cultural, legitimando su existencia y sus acciones. Las comunidades se apoyan en estas instituciones para proteger su legado y su memoria pues confían en su misión, es decir, en los objetos y su significancia (Maceira, 2012: 12) ${ }^{10}$. La preservación abarca como concepto todas las acciones dirigidas a su mantenimiento y transmisión en el tiempo para presentes y futuras generaciones, tanto de su materialidad como del mensaje del que es testimonio.

En el caso que nos lleva, los objetos de los museos memoriales tienen una carga simbólica y una significancia que va a ser determinante

$10 \ll$ En general, a partir de razones y significados diversos, el aprecio social y la legitimidad del museo suelen estar bastante extendidos» (Maceira, 2012: 12). Espacios confiables en términos informativos o científicos. 


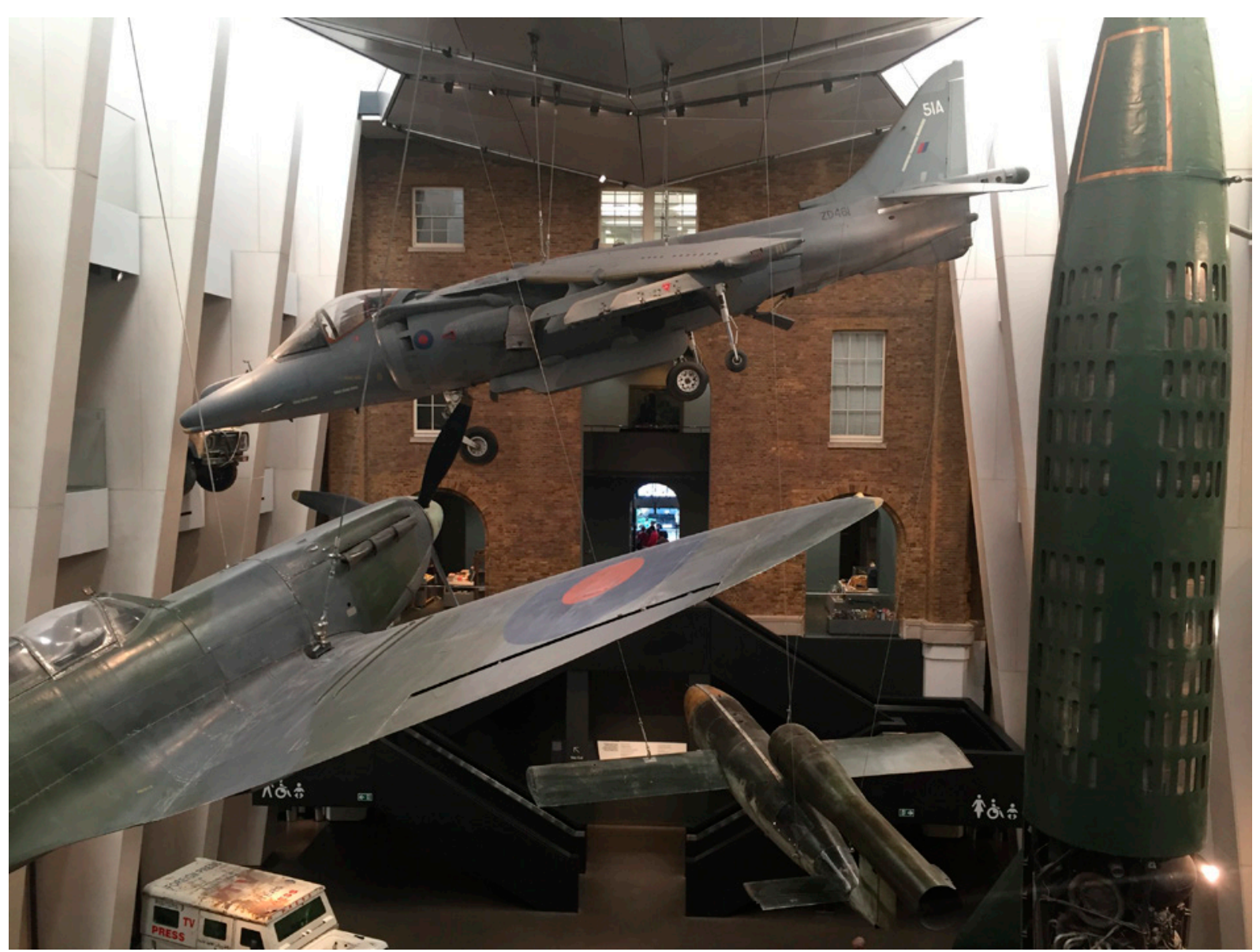

Vista interior del Imperial War Museum (Londres). Fotografía: Ana Galán-Pérez.

para construir los criterios de conservación. Museos que preservan valores intangibles, un patrimonio inmaterial identificado por las comunidades, para mejorar la vida de las generaciones actuales y transmitirlas a generaciones futuras (Barcenilla, 2019: 28-43). $Y$ en esta relación de valores patrimoniales, los artefactos representan «la presencia de la vida, pues también existe el rastro objetual derivado de ella». Es decir, los objetos ${ }^{11}$ que conforman las colecciones poseen este «rastro de la vida».

11 «La inmaterialidad, la presencia de la vida (...) también existe en el rastro objetual derivado de ella». Idea del rastro de la vida como patrimonio intangible o inmaterial íntimamente relacionada con el objeto patrimonializado, como objeto a conservar dentro de un contexto museológico (Boucher, 2000: 27-33 en Maceira, 2012: 12).
Además, destacamos una dificultad añadida que es la gran heterogeneidad de objetos. Los museos memoriales pueden contar entre sus colecciones con objetos procedentes de las artes decorativas, de la industria, pero también integran las expresiones artísticas ${ }^{12}$ y el patrimonio documental, colecciones de la antropología, como diarios y cartas. Son por tanto instituciones para la memoria y defensa de los derechos humanos, de compleja clasificación o tipificación museística, pues historia y arte, tecnología e industria, sociedad y antropología se incluyen, entre otros, en su acervo museístico.

12 Valga como ejemplo la exposición sobre el artista plástico Olère, que mostró colecciones propias y en préstamo del $\mathrm{Mu}$ seo Estatal de Auschwitz-Birkenau. 


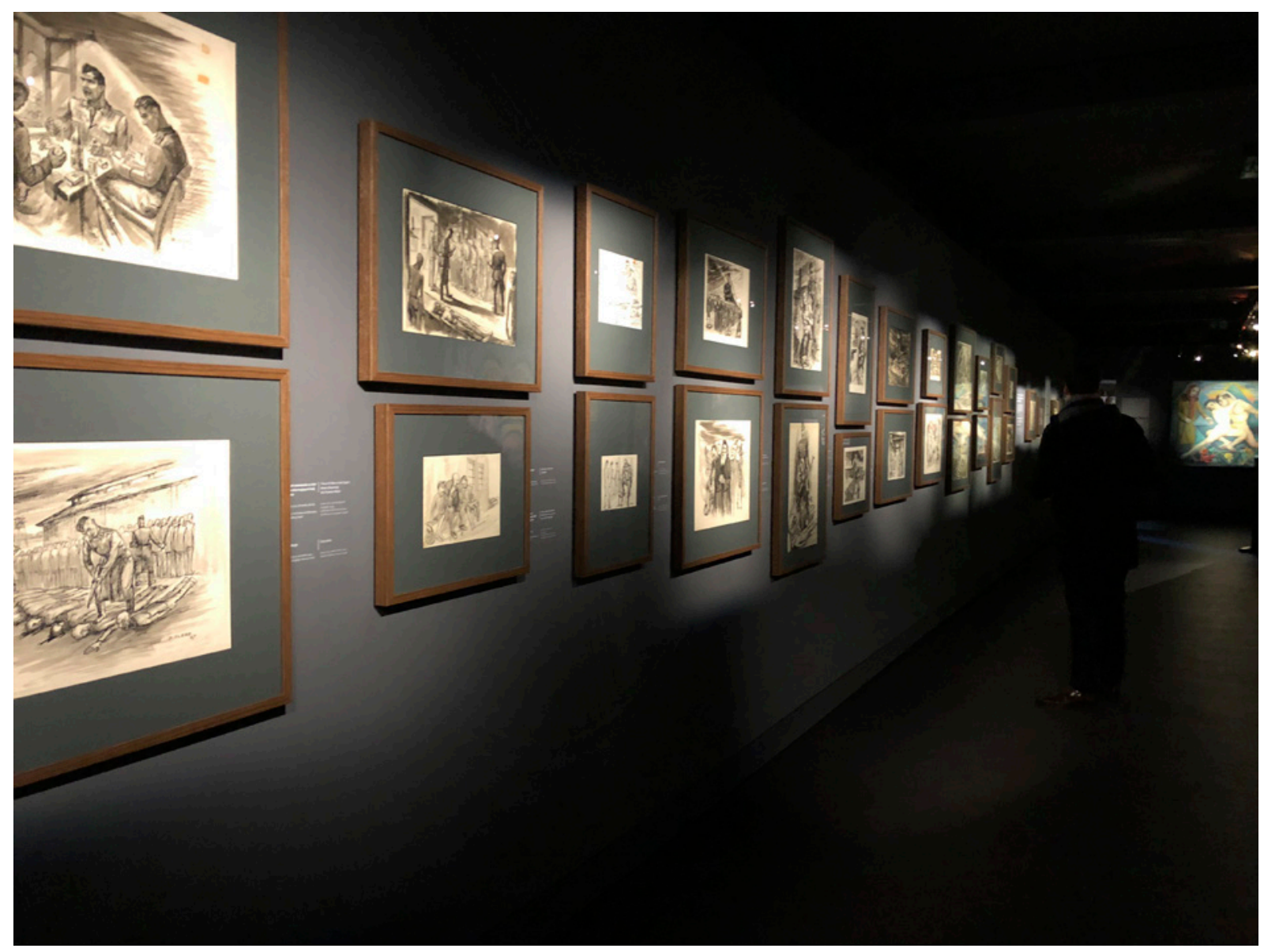

Panorámica de la exposición de David Olère, artista prisionero del campo de concentración nazi de Auschwitz-Brikenau. Fotografía: Ana Galán-Pérez.

Entonces, ¿qué rasgos nos pueden ofrecer luz para preservar, esto es, conservar y transmitir el mensaje del que son testigos? Al fin y al cabo, buscamos nuevas claves para comprender y por tanto abordar el análisis y diagnóstico desde la profesión, y saber cómo detener el deterioro así como manipularlos tanto dentro del museo como fuera de su lugar de origen.

El primer punto caracterizador de la conservación curativa de estas colecciones es asegurar la autenticidad, y por ello el principio de mínima intervención es la principal consigna en museos memoriales como el Museo Estatal de AuschwitzBirkenau, en Polonia. De esta manera, como si se tratara de una foto congelada del momento exacto en el que se encontró ese objeto, la misión de los profesionales es la de estudiar pormenorizadamente el objeto, conocer las causas de su deterioro, el porqué de las huellas que le aportan este gran valor histórico y documental como testimonio de los crímenes de la humanidad y mantenerlas visibles. Entonces, es significativo que en modo contrario que ocurre en el patrimonio histórico-artístico, en el patrimonio de la memoria se debe asegurar la pervivencia del propio material y de la huella misma de la degradación. Y esto es bien complejo, tal y como aseguran los profesionales del museo memorial (Bormann, 2018: 38). 


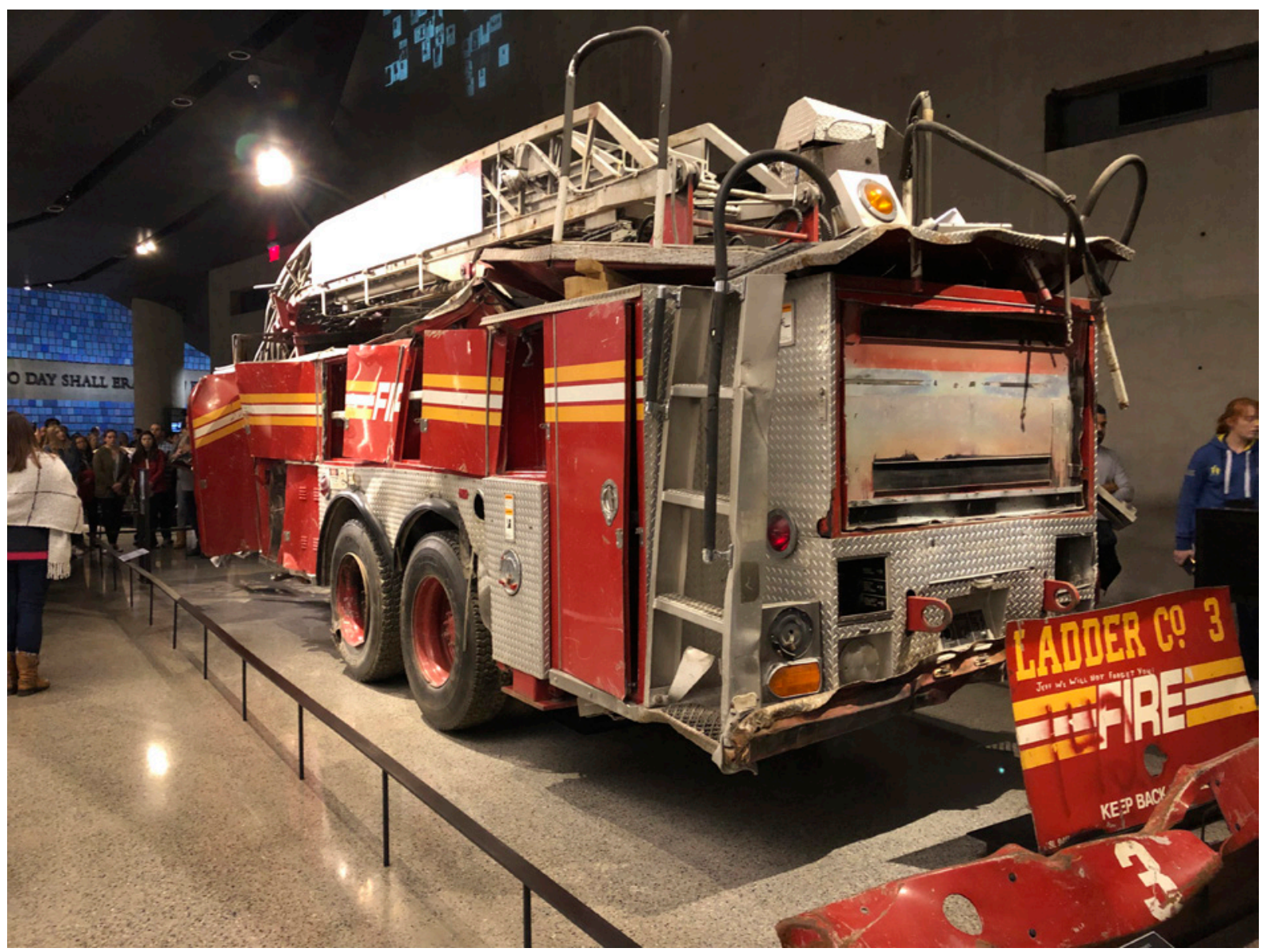

Camión de bomberos que acudió al rescate del ataque terrorista el 11 de Septiembre de 2001 en Nueva York. Museo Memorial 9/11 de Nueva York (Estados Unidos). Fotografía: Ana Galán-Pérez.

Así pues, la restauración tal y como la comprendemos aplicada al patrimonio histórico-artístico, es una acción apenas perceptible en los protocolos de conservación de patrimonio de la memoria. Devolver la legibilidad del aspecto o uso que tuvo en origen el objeto no se contempla en este caso, pues lo realmente significativo y valioso es mostrar la tragedia vivida de su propietario, a través del testimonio material que ofrece el objeto. La maleta, el zapato, los utensilios cotidianos tienen su significancia en el duelo. Estos objetos que portaban las víctimas son objetos cotidianos comunes del siglo xIX y primera mitad del siglo xx (Galán, 2020: 4970). Por supuesto ofrecen datos relevantes.
Nos cuentan de sus manufacturas, fábricas, técnicas de elaboración, del país de origen, pero sobre todo nos hablan del drama de esas personas y de los deportados al campo de concentración nazi, y del camino vivido desde su llegada hasta su perecimiento.

Conservar es detener las causas de degradación para que no sigan avanzando y destruyan por completo el objeto. Esta es la segunda consigna para su preservación. Rescatar del olvido o descubrir de nuevo desde su escondite (enroscados, plegados entre los ladrillos del campo, enterrados bajo los barracones, en las bases de latas o botellas). Documentar individualmente y en conjunto. Estudiar los soportes materiales, eliminar el 


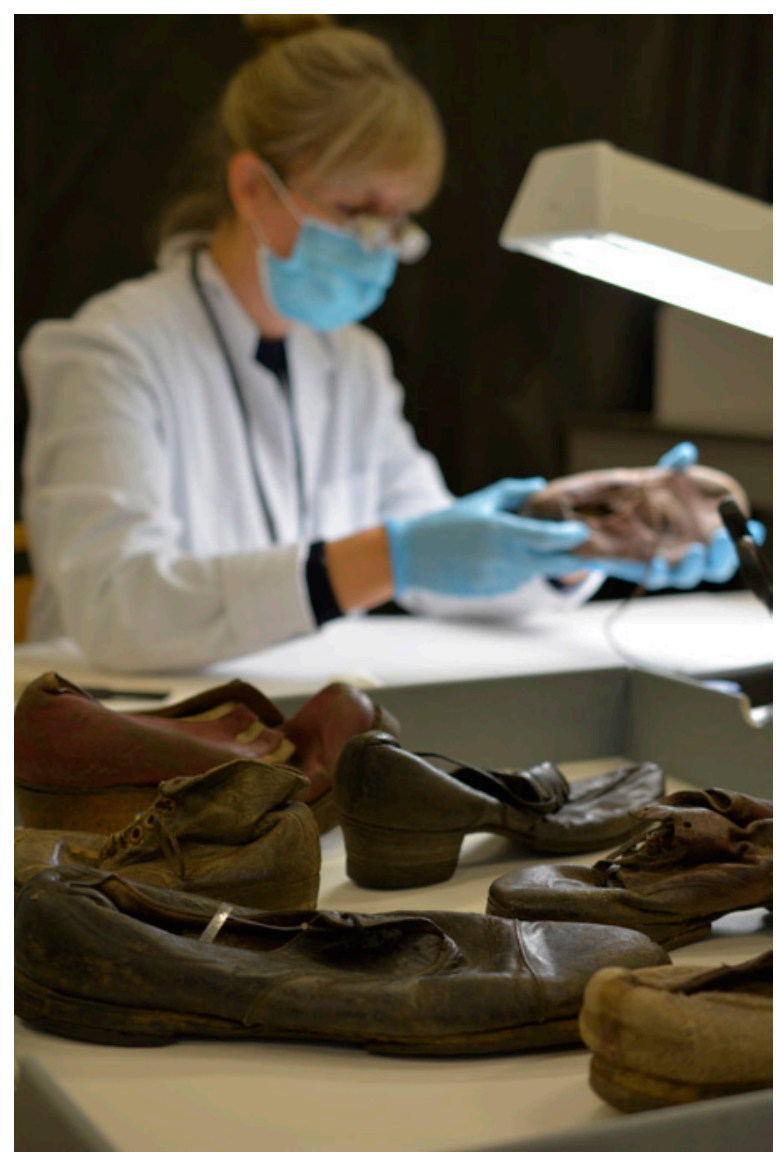

Estudio e intervención de la colección en el Laboratorio de Conservación del Museo Estatal Auschwitz-Birkenau. Fotografía: Andrze Jastrzebiowski, Departamento de Conservación. Museo Estatal de Auschwitz-Birkenau (Polonia). Octubre 2020.

deterioro del papel, el cartón, la madera, el metal, el cristal, el plástico... Y mantener sus huellas, sus golpes, arañazos, agujeros.

Esta delicada balanza entre mantener la huella y eliminar las causas del deterioro es en la tesitura que se encuentran los profesionales de los museos memoriales para conservar este patrimonio.

$\mathrm{Y}$ a la hora de manipular o exponer estos objetos frágiles, la dificultad es doble y es otro rasgo que los caracteriza respecto a otros patrimonios. Por un lado, por la propia falta de consistencia de los soportes, pues además de los objetos de los deportados, una buena parte de estas colecciones trata de objetos realizados con restos de materiales de despojo. Por otro lado, aunque se encuentren estables tras los cuidados de los profesionales, su paso por el campo y por inclemencias de todo tipo, hacen que todavía hoy haya reacciones químicas complejas de prever y de detener, según palabras de sus conservadores (Bormann, 2018: 38). Y en último lugar, todo lo relacionado con la prevención de riesgos (conservación preventiva) a la hora de manipular, transportar y exponer este patrimonio es de suma preocupación para sus custodios y para las comunidades que representan, pues no solo se trata de objetos patrimoniales, sino de testigos únicos de hechos trágicos, de la memoria individual y colectiva. Todo detalle, desde cómo viajan con los controles adecuados y haciendo un seguimiento de las vibraciones en los medios de transporte, hasta cómo se colocan en las vitrinas, sus soportes, sus formas, qué mensaje transmiten, asegura para futuras generaciones la conservación de su significancia y del patrimonio de la memoria.

\section{Conclusiones}

Los museos memoriales son instituciones conmemorativas que rememoran un hecho histórico, que preservan las colecciones de la memoria, diversas y heterogéneas, y nos ofrecen el contexto y el enfoque para investigarlas y conservarlas.

Un rasgo de estas instituciones es su vinculación con los lugares de la memoria, generando espacios museísticos en los paisajes históricos. Este hecho da lugar a que se produzca una tipología muy diversa de museos para preservar la barbarie y de colecciones heterogéneas: objetos procedentes de la arqueología contemporánea que se han descubierto en dichos lugares (sitios históricos y bélicos), objetos de la vida cotidiana (portados por los prisioneros de los campos de concentración), expresión artística para la supervivencia, todos ellos integrados en edificios industriales y militares, principalmente. Todos 


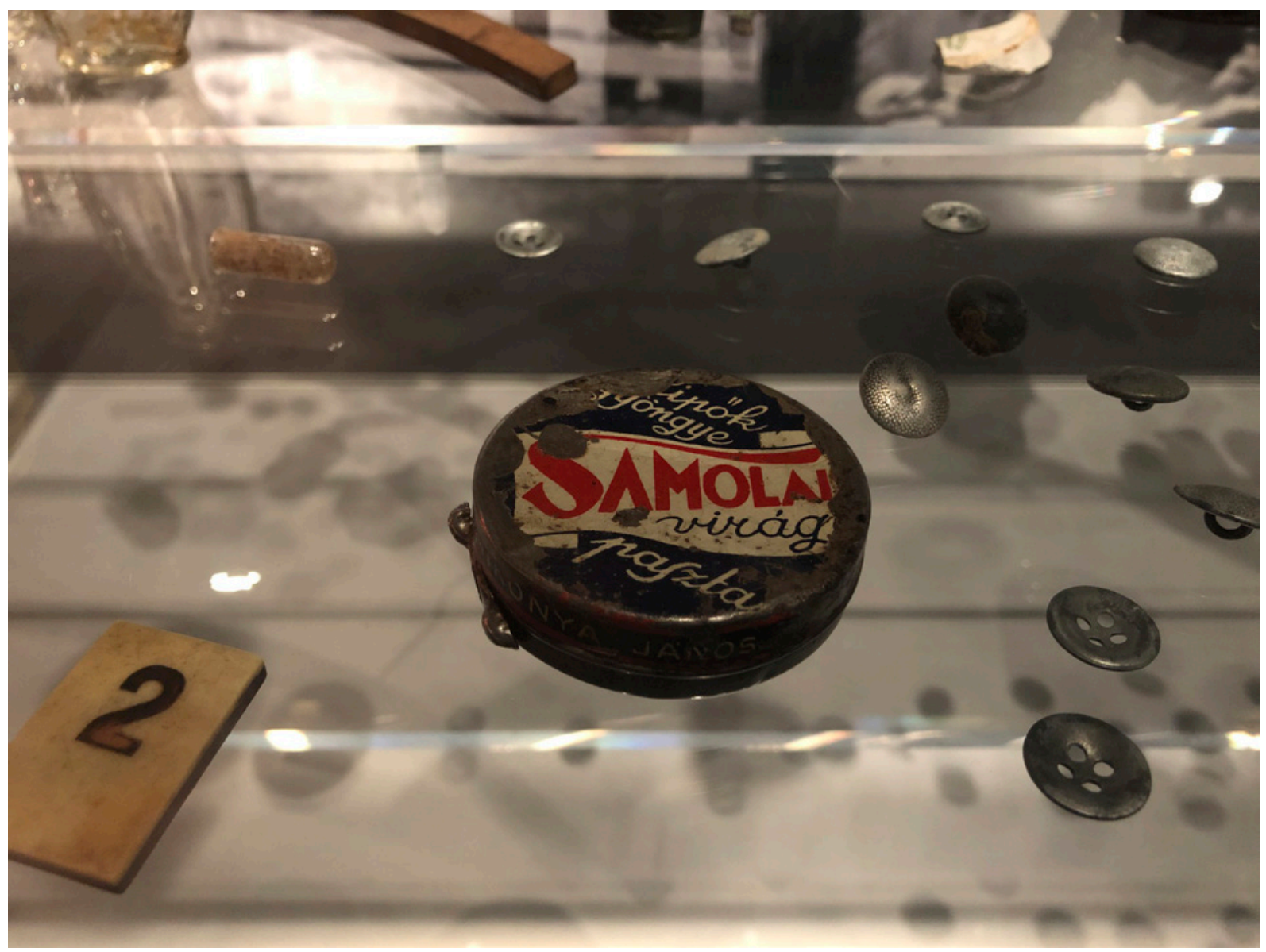

Objetos descubiertos con técnica arqueológica en la zona denominada Kanada. Museo Estatal de Auschwitz-Birkenau. Fotografía: Ana Galán-Pérez.

estos objetos forman colecciones diversas relacionadas con el lugar en el que ocurrieron los acontecimientos históricos.

Desde un punto de vista museológico, los percibimos alejados de las clasificaciones más reconocidas en el imaginario colectivo respecto a los Museos de Arte o Museos de Historia propiamente dichos. Si bien es cierto que comparten rasgos propios de los Museos de Sitio e Históricos, Museos Militares, Museos de Historia y Cultura Local e incluso, de Archivos, por el importante volumen de objetos documentales que testimonian el legado de las comunidades (pasaportes, salvoconductos, documentos oficiales así como diarios, cartas y mensajes en diversos soportes).
Desde el punto de vista de la conservación preventiva, especialmente lo que se refiere al conjunto de acciones en el marco de las exposiciones temporales, son las propias instituciones de origen, los museos memoriales, los que se constituyen como fuentes primarias de conocimiento y los que determinan cómo y por qué se forman las colecciones, se conservan y restauran sus objetos ${ }^{13}$. Es decir, el corpus nor-

13 Exposición temporal itinerante «Auschwitz. No hace mucho. No muy lejos». Para estudiar la significancia de este tipo de objetos no hay manuales de colecciones de la memoria, o de colecciones de la Shoá. Por ello, hay que acudir directamente a la fuente, a cada institución prestadora, para conocer también los planes de Seguridad y Emergencias, el Plan de Conservación Preventiva, o los criterios de dichos museos de las intervenciones de Restauración que se han realizado a las piezas. 


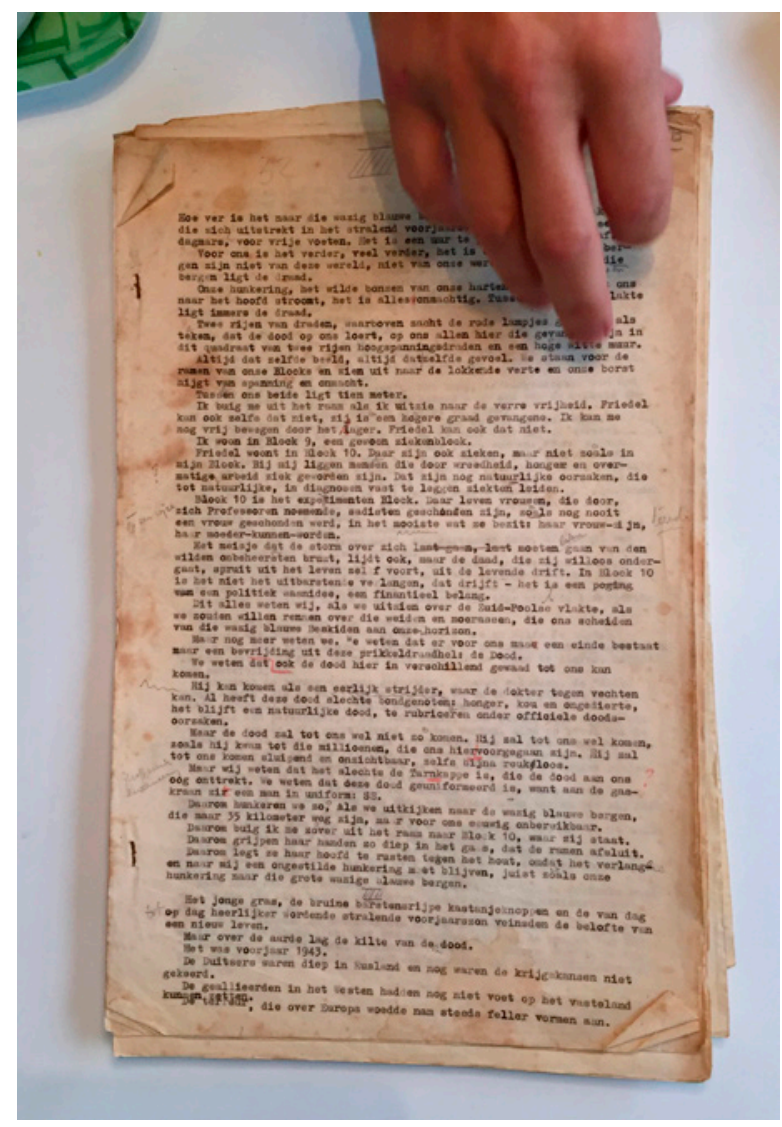

Documento mecanografiado original del diario de Eddy de Wind, médico superviviente del campo de concentración. El diario se ha traducido en 2019 en varios idiomas, incluido el español. Fotografía: Ana Galán-Pérez.

mativo sobre el que construir los criterios va a proceder de la documentación generada por los museos y sus departamentos de conservación, que en muchas ocasiones reconocen que se van construyendo conforme se estudian casos concretos de intervención de las piezas. Algunos interrogantes para resolver son: ¿cuál es el peso de las comunidades a la hora de definir el alcance de los procesos de conservación y restauración?, ¿cómo representan los objetos la defensa de los derechos humanos en los diversos museos?, ¿cómo han llegado las colecciones a los museos?, ¿cuál es el rasgo que diferencia a unos museos respecto a otros en los procesos de conservación?, ¿en base a qué fines se constituye la política de colecciones de las diversas tipologías museísticas?, ¿cómo se establece la significancia de los objetos?, ¿cuáles son más relevantes en un plan de conservación preventiva y de prevención de riesgos?, ¿cómo afecta la huella de la historia y del drama en los materiales constitutivos de los objetos?, ¿desde qué especialización podemos partir para abordar la conservación material de los objetos de la memoria?, ¿cuándo tienen peso en su conjunto, por su volumen, y cuándo son representativos de un colectivo, en su individualidad?, ¿cómo elaborar protocolos de conservación preventiva y gestión de riesgos en los que se integren todos los agentes relevantes en la preservación de la memoria?

Por tanto, acercándonos a las instituciones de remembranza, comprenderemos los aspectos necesarios para abordar la preservación del legado de la memoria. Y para ello, hemos reflexionado sobre el museo del siglo XXI como contenedor de la memoria, garante de un pensamiento crítico, así como de las conexiones con las comunidades para preservar su legado y los objetos que forman parte de sus colecciones. Siguiendo a Luz Maceira sobre qué se conserva y qué se lega en esta relación entre museos y memoria, «más que un espacio físico, el museo es una red de relaciones entre objetos y personas» (Maceira, 2012: 52).

\section{REFERENCIAS Y BIBLIOGRAFÍA}

Arrieta Urizberea, Iñaki (ed.) (2016) Lugares de memoria traumática. Representaciones museográficas de conflictos políticos y armados, Bilbao: UPV.

Barcenilla, Haizea (2019) «Repensar el museo desde la vida», en Diferents. Revista de museus, 4: 28-43. DOI: http://dx.doi.org/10.6035/Diferents.2019.4.2

Biedermann, Anna; Galán Pérez, Ana y Luis FeRREIRO (2019) «Auschwitz. A travelling exhibition: Exhibition and Conservation./Auschwitz. Una ex- 


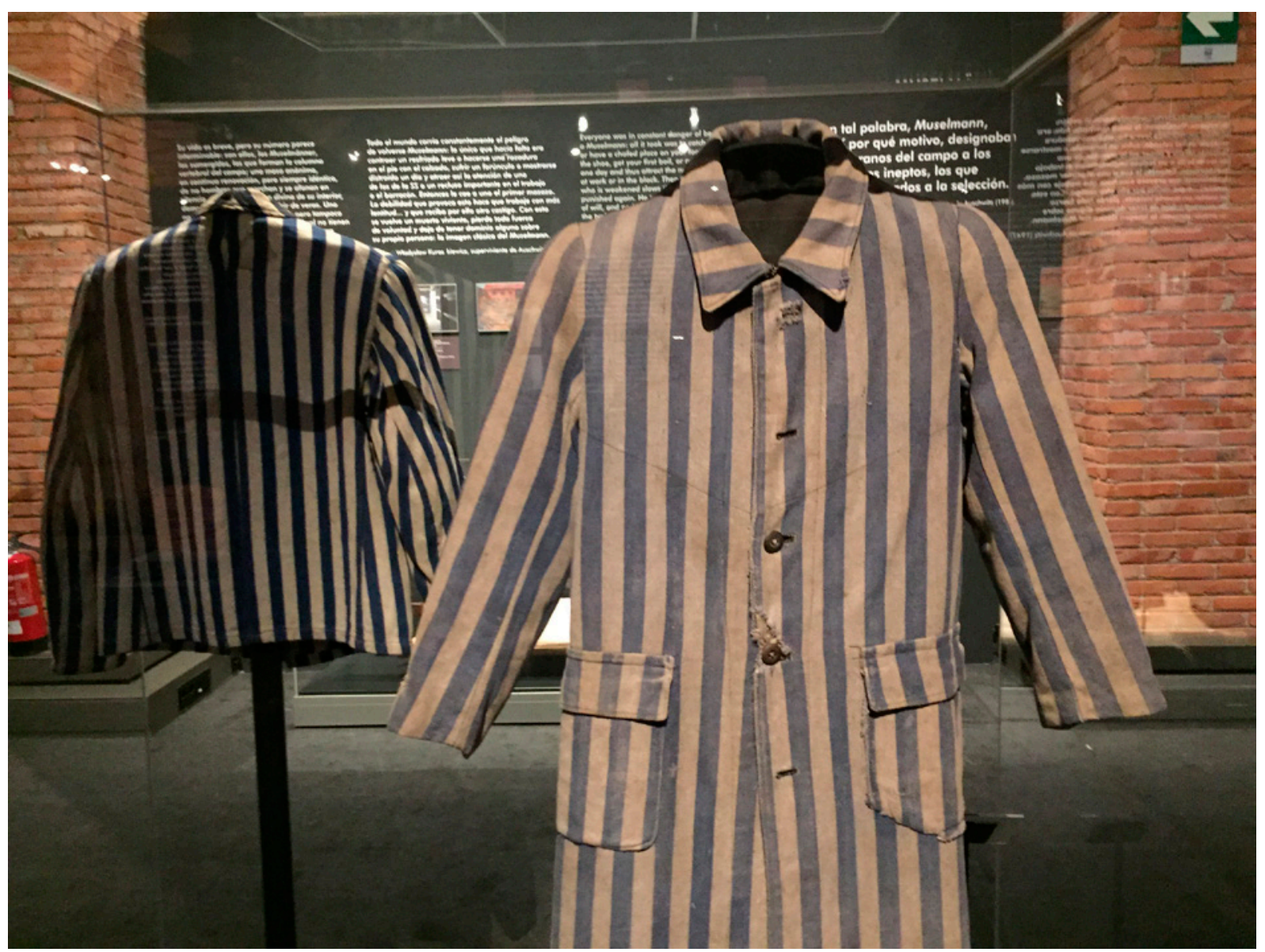

Bata y camisa de uniforme del campo de concentración, colección del Museo Estatal de Auschwitz-Birkenau. Exposición «Auschwitz. No hace mucho. No muy lejos» en la Fundación Canal de Madrid (2017-2019). Fotografía: Ana Galán-Pérez.

posición itinerante: diseño, gestión de colecciones y de información", en Foradada Baldellou, Carlos y Pilar Irala-Hortal (coord.) (2019) Re_Visiones sobre Arte, patrimonio y tecnología en la era digital, Zaragoza: Universidad de Zaragoza-Gobierno de Aragón, 175-184.

EsCRIBANo GonzÁLvez, Elena (2018) «Musealizar la memoria de las víctimas», en Revista Historia Autónoma, 12: 261-278. Dor: https://doi.org/10.15366/ rha2018.12.014

Hernández Cardona, Francesc Xavier (2011) «Conflictos contemporáneos, estrategias de musealización crítica», en Revista Museo y Territorio, 4: 79-86.

GALÁN-PÉREZ, Ana (2020) «Significancia del patrimonio trágico. Hacia nuevos paradigmas de conservación preventiva», en Revista UNICUM, 19: 59-70.

— (2019) «Conserving Testaments to Human Survival», en van Pel, Robert Jan (ed.) (2019) Auschwitz. Not long ago, Not far away, New York, United States: Abbeville Press Inc., U.s., 219-223.

- (2018) «Conocer, conservar y comunicar el patrimonio de hechos traumáticos», en GE-IIC (coord.) (2018) ¿Y después? Control y mantenimiento del patrimonio cultural, una opción sostenible, Grupo Español del IIC, 204-213.

Kavanagh, Gaynor (2000) Dream Spaces. Memory and the Museum, Londres: Leicester University Press. DoI: https://doi.org/10.2307/1593837

Lorente, Jesús Pedro (2011) Manual de historia de la museología, Gijón: Trea.

LÓPEZ GoNZÁLEZ, Loreto (2011) «Derechos Humanos, patrimonio y memoria. Museos de la memoria y sitios de conciencia», en Álvarez, Michael et al. (2011) Derechos Humanos, pedagogía de la memoria y politi- 
cas culturales, Santiago: Lom Ediciones, 127-138.

Maceira OCHOA, Luz María (2012) Museo, memoria y derechos humanos: itinerarios para su visita, Bilbao: Universidad de Deusto, Servicio de Publicaciones.

Martín Cabello, Antonio (2005) «Tradición y memoria popular: los museos militares y la recreación de la historia», Revista de Investigaciones Políticas y Sociológicas (RIPS), 4, 2: 153-166.

Matus Toro, Alonso (2015) Museografía de la Tortura en Espacios de Memoria. Museo de la Memoria y los Derechos Humanos, Parque por la Paz Villa Grimaldi, y Londres 38, Espacio de Memorias. Trabajo de Licenciatura. Pontificia Universidad Católica de Valparaíso.

Mora Hernández, Yaneth (2013) «Lugares de memoria: entre la tensión, la participación y la reflexión», en Revista Panorama, 7, 13: 97-109.

Navarro Rojas, Oscar (2011) «Ética, museos e inclusión: un enfoque crítico», en Revista Museo y Territorio, 4: 49-59.

Ortiz García, Carmen (2011) «El complejo penitenciario de Carabanchel. Un caso de patrimonio incómodo», en Proyecto de Investigación La cárcel de Carabanchel (1944- 2008). Estudio histórico, arqueológico y etnográfico. Ref. HAR2009-09913 del Plan Nacional de $\mathrm{I}+\mathrm{D}+\mathrm{I}$ del Ministerio de Ciencia e Innovación.

- (2008) «Archivos etnográficos, memoria y nuevos patrimonios: el caso del archivo del duelo», en PEREIRo, Xerardo; Prado Conde, Santiago y Kiroko TAKENAKA (coords.) (2008) Patrimonios culturales: Educación e interpretación. Cruzando límites y produciendo alternativas, Donostia: Ankulegi Antropologia Elkartea, 155-170.

Roigé, Xavier; Fernández de PAZ, Esther e Iñaki Arrieta (coord.) (2008) El futuro de los museos etnológicos, Donostia: Federación de Asociaciones de Antropología del Estado Español.

Santacana, Joan y Xavier HeRnández (2006) Museología crítica, Gijón: Trea.

Shelton, Anthony (2011) «From anthropology to Critical Museology and viceversa», en Revista Museo y Territorio, 4: 30-41.

Velázquez marroni, Cintia (2011) «El museo memorial: un nuevo espécimen entre los museos de historia», en Intervención, 2, 3: 26-31.

VIEREGG, Hildegard (2015) «La historia contemporánea en relación con la memoria, los museos y los espacios de memoria Internacionales-pasado, presente y futuro», en Complutum, 26, 2: 89-99, La Museología entre la tradición y la posmodernidad, Madrid: Universidad Complutense de Madrid. Dor: https://doi. org/10.5209/rev_CMPL.2015.v26.n2.50420
Winstone, Martin (2010) The Holocaust Sites of Europe: An Historical Guide, I.B. London: Tauris.

Witker BARra, Rodrigo (2016) «Museos de la vergüenza. El uso de la memoria política como patrimonio cultural», en ILLAPA Mana Tukukuq, 13: 8897. DOI: https://doi.org/10.31381/illapa.v0i13.1901

Williams, Paul (2007) Memorial Museums. The Global Rush to Commemorate Atrocities, Nueva York: Berg.

Recibido el 25 del 7 de 2020

Aceptado el 3 del 11 de 2020 BIBLID [2530-1330 (2020): 36-55]

Nota: Las fotografías que no son de la autora han sido propuestas por el equipo editorial. 


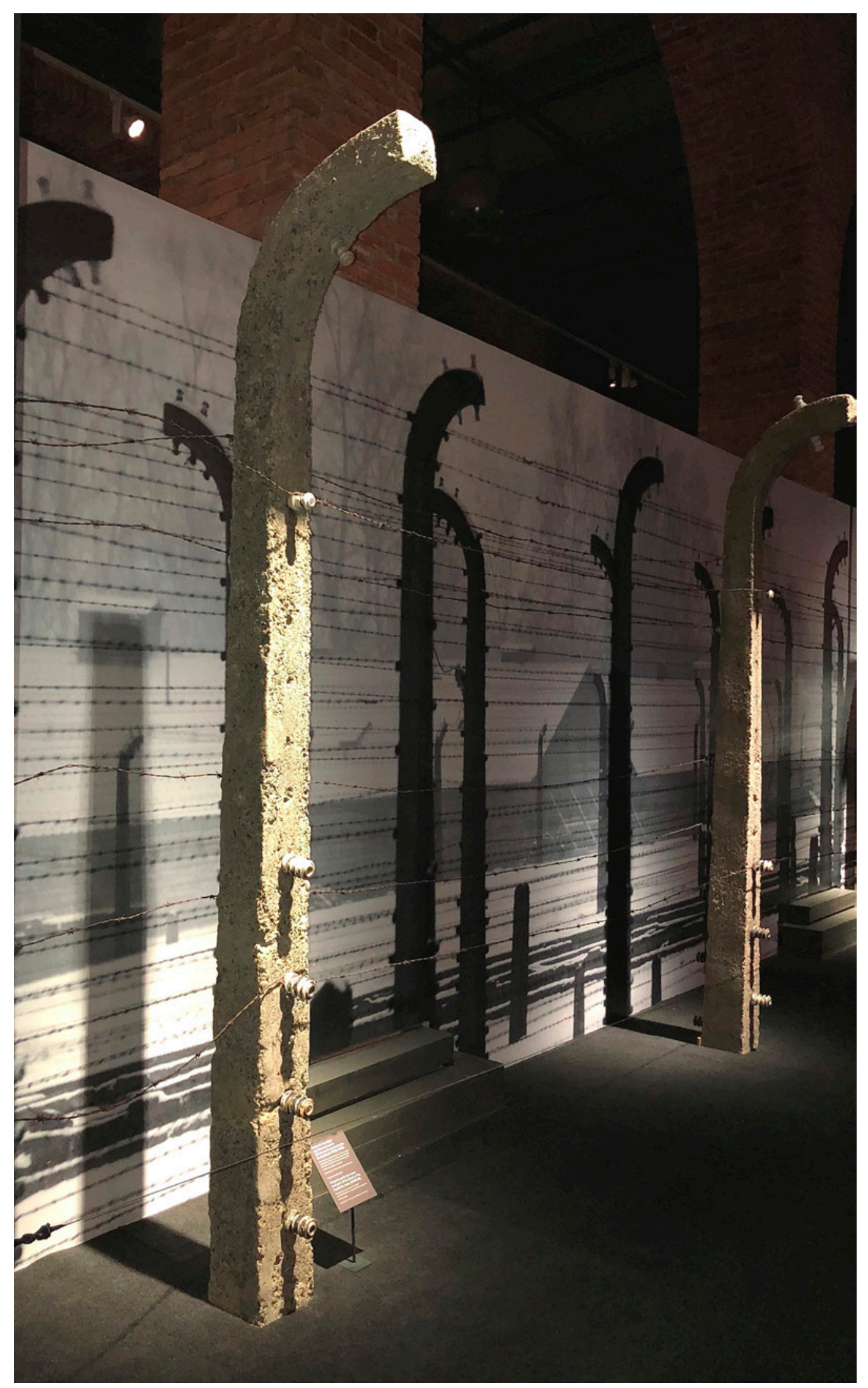

Valla electrificada en la exposición «Auschwitz. No hace mucho. No muy lejos» en Madrid, Fundación Canal, 2018-2019. Fotografía: Wences Rambla. 